Wright State University

CORE Scholar

1995

\title{
A Theoretical Study Concerning the Solar Cycle Dependence of the Nightside Ionosphere of Venus
}

Zoltan Dobe

Andrew F. Nagy

Jane L. Fox

Wright State University - Main Campus, jane.fox@wright.edu

Follow this and additional works at: https://corescholar.libraries.wright.edu/physics

Part of the Astrophysics and Astronomy Commons, and the Physics Commons

\section{Repository Citation}

Dobe, Z., Nagy, A. F., \& Fox, J. L. (1995). A Theoretical Study Concerning the Solar Cycle Dependence of the Nightside Ionosphere of Venus. Journal of Geophysical Research: Space Physics, 100 (A8),

14507-14513.

https://corescholar.libraries.wright.edu/physics/433

This Article is brought to you for free and open access by the Physics at CORE Scholar. It has been accepted for inclusion in Physics Faculty Publications by an authorized administrator of CORE Scholar. For more information, please contact library-corescholar@wright.edu. 


\title{
A theoretical study concerning the solar cycle dependence of the nightside ionosphere of Venus
}

\author{
Zoltan Dobe and Andrew F. Nagy \\ Space Physics Research Laboratory, Department of Atmospheric, Oceanic and Space Science, University of Michigan, Ann Arbor
}

\author{
J. L. Fox
}

Institute for Terrestrial and Planetary Atmospheres, State University of New York at Stony Brook

\begin{abstract}
We modeled the chemical and physical processes taking place in the nightside ionosphere of Venus by solving the one dimensional coupled continuity and momentum equations for 12 ion species $\left[\mathrm{CO}_{2}^{+}, \mathrm{O}_{2}^{+}, \mathrm{O}^{+}, \mathrm{H}^{+}, \mathrm{NO}^{+}, \mathrm{CO}^{+}, \mathrm{N}_{2}^{+}, \mathrm{N}^{+}, \mathrm{He}^{+}, \mathrm{C}^{+}, \mathrm{O}^{+}\left({ }^{2} \mathrm{D}\right)\right.$ and $\left.\mathrm{O}^{+}\left({ }^{2} \mathrm{P}\right)\right]$. We investigated the relative importance of the two major processes responsible for maintaining the nightside plasma densities: atomic ion transport from the dayside and impact ionization due to energetic electron precipitation. We compared our model calculations with electron density and ion composition observations obtained by instruments aboard the Pioneer Venus Orbiter during both high and moderate solar cycle conditions. These studies lead us to conclude that day-to-night atomic ion transport is dominant during high solar activity, while during moderate solar activity conditions the combined effects of the electron precipitation and reduced day-to-night ion transport are responsible for maintaining the nightside ionosphere of Venus.
\end{abstract}

\section{Introduction}

Venus has the most explored and best understood ionosphere in our solar system, other than that of the Earth. Most of our knowledge about the Venus ionosphere-thermosphere system is based on information obtained by the Pioneer Venus Orbiter (PVO), although earlier measurements by Mariners 5 and 10, and Veneras 9 and 10 also provided some important data. During the first 2 years of the PVO mission, which began when the PVO spacecraft was placed into orbit on December 4,1978 , and for a period of about $\mathbf{5 0}$ days, prior to the final destructive spacecraft entry into the atmosphere of Venus in October, 1992, periapsis was actively maintained near $150 \mathrm{~km}$, thus allowing in situ measurements to be made well inside the ionosphere. The early period of in situ ionospheric measurements corresponds to high solar activity $\left(F_{10.7}-200\right)$, while the solar activity was moderate $\left(F_{10.7} \sim 120\right)$ during the brief entry period. The significant database that has been obtained, together with the results of numerous theoretical model calculations, have provided a reasonably good description and understanding of the physical and chemical processes controlling the ionosphere of Venus. A number of review papers have been written summarizing these existing observational and theoretical results (e.g., Nagy et al., 1983; Brace et al., 1983; Brace and Kliore, 1991).

Ever since the first radio occultation observations of the Venus nightside jonosphere by Mariner 5 [Kliore et al., 1967], the mechanisms responsible for the maintenance of this ionosphere have been intensely discussed and debated. The existence of a substantial nightside ionosphere (with peak plasma densities of the order of $10^{4} \mathrm{~cm}^{-3}$ ) was difficult to explain, because the effective night on Venus lasts about 58 days, while typical ion recombination times are of the order of $100 \mathrm{~s}$. The earliest

Copyright 1995 by the American Geophysical Union.

Paper number 95JA00331.

0148-0227/95/95JA-00331\$05.00 interpretation of the Mariner 5 nightside electron density profile was based on the nightward transport of $\mathrm{He}^{+}$or $\mathrm{H}_{2}^{+}$ions [McElroy, 1968; McElroy and Strobel, 1969]. These attempts were able to reproduce the measured densities fairly well, but the resulting ion composition was not consistent with later observations. Several other explanations for the origin of the nightside ionosphere of Venus were proposed, including photoionization by scattered solar and interplanetary radiation, meteor ionization [Krasnapolsky, 1979], or long lifetime metallic ions [Butler and Chamberlain, 1976], but none of these suggestions were consistent with the observational data obtained nearly a decade later by PVO. In 1975, the plasma analyzers on Veneras 9 and 10 detected electron fluxes with energies exceeding several tens of $\mathrm{eV}$ in the wake of Venus. Gringauz et al. [1976] suggested that these electron fluxes could explain the existence of the Venus nightside ionosphere, and Gringauz et al. [1979] showed that these electrons, if they precipitated into the ionosphere, would be able to produce the observed ionization peak at low solar activity. Chen and Nagy [1978] also suggested that electron impact ionization may play an important role in maintaining the nightside ionosphere. Brace et al. [1979] concluded, comparing the results of their model calculations with the electron density profiles measured by the OETP instrument on PVO, that either a downward $\mathrm{O}^{+}$ion flux of about $6 \times 10^{7} \mathrm{~cm}^{-2} \mathrm{~s}^{-1}$ or a monoenergetic $30 \mathrm{eV}$ electron beam of $4.4 \times 10^{7} \mathrm{~cm}^{-2} \mathrm{~s}^{-1}$ leads to ionospheric densities consistent with the observed values. The measurement of strong transterminator $\mathrm{O}^{+}$ion flows (of order 1$2 \times 10^{8} \mathrm{~cm}^{-2} \mathrm{~s}^{-1}$ ) reported by Knudsen et al. [1981] provided observational support for the assumption of downward ion flows on the nightside. One dimensional model calculations for the nightside ionosphere, using precipitating electrons and downward $\mathrm{O}^{+}$fluxes, were carried out by Spenner et al. [1981]. Their results showed that a downward flux of $\mathrm{O}^{+}$of about $1 \times 10^{8} \mathrm{~cm}^{-2} \mathrm{~s}^{-1}$ could reproduce the measured median profiles of $\mathrm{O}^{+}$and $\mathrm{O}_{2}^{+}$. They also found that, during high solar activity, the $\mathrm{O}_{2}^{+}$peak density produced by the precipitating electron fluxes only, as measured by the ORPA, is about half of the observed values, while the 
discrepancy between the calculated and measured $\mathrm{O}^{+}$peak densities is even bigger. Cravens et al. [1982] found that high solar wind pressures and correspondingly low ionopause altitudes on the dayside are correlated with low ion densities on the nightside. This suggests that during low solar activity conditions, when the dayside ionopause is depressed to lower altitudes, ion transport, which takes place mostly at the higher altitudes is "choked off," and impact ionization, produced by electron precipitation, takes over as the dominant source of ionization for the nightside. The first quasi-two-dimensional model, solving the coupled continuity and vertical momentum equations, and using the measured horizontal drift velocities, was developed by Cravens et al. [1983]. These calculations showed that transport from the dayside is sufficient to maintain the observed nightside ion densities. Other multidimensional models also confirmed this conclusion [(e.g., Whitten et al., 1984; Elphic et al., 1984)]. A self-consistent two-dimensional, time dependent, shock capturing, single species model was developed by Nagy et al. [1991], which was able to evaluate the importance of supersonic day-to-night flows, and to investigate in a quantitative way the possible shock formation in the nightside ionosphere during solar maximum conditions. Fox [1992] solved the one-dimensional coupled continuity and momentum equations for eight ion species and discussed the chemistry of the nightside ionosphere assuming downward fluxes for the atomic ions as the only nightside ionization source. The results showed a good agreement with the data measured under solar maximum conditions. In this study [Fox, 1992] orbits from the first 3 years of the PVO mission were also examined; ratios of $\mathrm{O}^{+} / \mathrm{O}_{2}^{+}$peak densities were used as indicators of impact ionization and it was found that at solar maximum the relative importance of the precipitation source is low or moderate, except in the case of two orbits (orbit 65 and 73), during which the ion density profiles appear to be greatly affected by the presence of electron impact ionization sources.

The availability of ionospheric in situ PVO data obtained in 1992 made it possible, for the first time, to compare, in some detail, the nightside Venus ionosphere under high and moderate solar activity conditions. Very recently, Brannon et al. [1993] presented an expanded version of the model constructed by Fox [1992]. Brannon et al. [1993] concluded, through a comparison of the entry phase data from the PVO ion mass spectrometer and the results of their model calculations, that significant day-to-night plasma transport must be present at low solar activity along with the electron precipitation source. We decided to look further into this question of the relative importance of the two major mechanisms responsible for maintaining the nightside ionosphere: day- to-night plasma transport and electron precipitation during different solar cycle conditions. In the rest of this paper we briefly outline our one dimensional model and then we discuss the results of our calculations, compare them with the observed electron density and ion composition information and finally come to some conclusions concerning the relative importance of above mentioned two maintenance processes.

\section{Model Description}

The time-dependent, one-dimensional, coupled continuity and momentum equations for 12 ion species $\left[\mathrm{CO}_{2}^{+}, \mathrm{O}_{2}^{+}, \mathrm{O}^{+}, \mathrm{H}^{+}, \mathrm{NO}^{+}\right.$, $\mathrm{CO}^{+}, \mathrm{N}_{2}^{+}, \mathrm{N}^{+}, \mathrm{He}^{+}, \mathrm{C}^{+}, \mathrm{O}^{+}\left({ }^{2} \mathrm{D}\right)$ and $\left.\mathrm{O}^{+}\left({ }^{2} \mathrm{P}\right)\right]$. have been solved:

$$
\frac{\partial n_{i}}{\partial t}+\frac{\partial F_{i}}{\partial z}=P_{i}-L_{i}
$$

$$
\begin{aligned}
F_{i z} & =n_{i} v_{i z} \\
& =-D_{i} n_{i}\left\{\frac{1}{n_{i}} \frac{\partial n_{i}}{\partial z}+\frac{m_{i} g}{k T_{i}}+\frac{T_{e} / T_{i}}{n_{e}} \frac{\partial n_{e}}{\partial z}+\frac{1}{T_{i}} \frac{\partial}{\partial z}\left[T_{i}+T_{e}\right]\right\}
\end{aligned}
$$

where the physical meaning of the symbols for the $i$ th species are the following:

$\begin{array}{ll}n_{i} & \text { number density; } \\ v_{i} & \text { vertical diffusion velocity; } \\ F_{i z} & \text { vertical diffusion flux; } \\ P_{i} & \text { production rate; } \\ L_{i} & \text { loss rate; } \\ D_{i} & \text { diffusion coefficient; } \\ m_{i} & \text { ion mass; } \\ g_{i} & \text { gravitational acceleration; } \\ k & \text { Boltzmann constant; } \\ T_{i} & \text { ion temperature; } \\ T_{i} & \text { electron temperature; } \\ n_{e} & \text { electron density. }\end{array}$

Equation (2) can be obtained by neglecting the explicit time dependent and inertial terms in the complete momentum equation [(cf. Schunk and Nagy, 1980)]. The diffusion coefficient for the $i^{\text {th }}$ species is given by

$$
D_{i}=\frac{k T_{i}}{m_{i} n_{i}}
$$

where $v_{i}$ is the sum of the ion-neutral and ion-ion collision frequencies for the $i^{\text {th }}$ ion. The calculations presented here have also assumed that the vertical diffusion of ions is not inhibited by the presence of any horizontal magnetic field; while this assumptions is a reasonably good one in general, it becomes questionable for the case of the so-called "disappearing ionospheres," which tend to be associated with a well-organized magnetic field. In our calculations we used neutral gas number density values given, for midnight conditions, by the empirical VTS3 model of Hedin et al. [1983]. This model provides neutral densities for $\mathrm{CO}_{2}, \mathrm{O}, \mathrm{CO}, \mathrm{N}_{2}, \mathrm{~N}, \mathrm{He}$, and the neutral temperature as a function of altitude, latitude, local solar time, and $F_{10.7}$ index. The extrapolation to solar minimum conditions is based on solar activity variations near solar maximum conditions, but very recent measurements during the entry phase of PVO, indicate quite a good agreement between the observed and modeled neutral density data [Kasprzak et al., 1993]. Our calculations were carried out for both high and moderate solar cycle conditions, corresponding to the early and the entry phases, respectively, of the PVO operations. The $H$ densities for high solar cycle conditions were taken from the Venus International Reference Atmosphere (VIRA) model [Keating et al., 1985], and for moderate solar cycle activity they were set to reproduce the observed $\mathrm{H}^{+}$densities in the chemical equilibrium region [(cf. Brinton et al., 1980)]. The NO values were adopted from Bougher et al. [1988] for the solar maximum case, and for the solar minimum case it was adjusted to lead to the observed $\mathrm{NO}^{+}$ densities. The electron temperature values for high solar activity conditions were taken from the empirical ionospheric model constructed by Theis et al. [1984]. This model was recently extended by Theis and Brace [1993] using nightside PVO entry data obtained during low solar activity conditions. We have also used the electron density values given by this model in our comparisons with the model results. The ion temperatures were taken from the VIRA model [Baver et al., 1985]. The chemical production and loss rates given by Schunk and Nagy [1980], Fox [1982], Kim et al. [1989], and Fox and Taylor [1990] were used in 
this study. The collision frequencies were taken from Schunk and Nagy [1980].

There is no reliable direct or even indirect information available on the solar cycle variation of the electron flux on the nightside of Venus. The database on the electron flux, presented by Knudsen and Miller [1985], is large, but restricted to solar cycle conditions. There apparently is a significant scatter in the observed electron fluxes, with variations up to an order of magnitude. The only solar cycle minimum electron flux measurements were the Venera 9 and 10 observations of Gringauz et al. [1979]. The two sets of data points from these observations, presented by Knudsen and Miller [1985] fall within their scatter of data points, although they are lower than the mean. The significance of this is uncertain. Is the difference an indication of (1) the large variabilities, (2) instrument and/or calibration differences, or (3) is it a clue to a real solar cycle effect? No electron flux data have been looked at from the entry period, although some may be available at some future date. Auroral observations could provide indirect information on the solar cycle variability of the precipitating electron flux, but here again there is no relevant published information to guide us. Therefore in this work we assumed that the electron flux does not vary with solar cycle (see also Summary and Conclusion section) and further assumed that $51 \%$ of the mean electron flux value presented by Knudsen and Miller [1985] precipitates into the atmosphere, in accordance with the findings of Brannon et al. [1993]. Knudsen and Miller [1985] approximated the energy spectrum of the electron flux measured by the retarding potential analyzer (ORPA) instrument on PVO, as a sum of two Maxwellian energy distributions. The densities and temperatures of these two Maxwellians they gave as $n_{\mathrm{el}} \sim 3 \mathrm{~cm}^{-3}, T_{\mathrm{el}} \sim 14 \mathrm{eV}$ and $n_{\mathrm{e} 2} \sim 0.06 \mathrm{~cm}$ ${ }^{-3}, \mathrm{~T}_{02}-200 \mathrm{eV}$, respectively. In order to calculate the electron impact ionization rates we solved the two stream transport equations for the electrons [Nagy and Banks, 1970], using as input the measured precipitating electron spectra given above. Production rates were calculated for $\mathrm{CO}_{2}^{+}, \mathrm{O}^{+}, \mathrm{CO}^{+}, \mathrm{N}_{2}^{+}$, and $\mathrm{He}^{+}$, based on the neutral densities given by the VTS3 model. The inelastic and ionization cross sections used in the calculations were described by Gan [1991].

The main differences between the Brannon et al. [1993] model and ours are (1) our inclusion of $\mathrm{H}^{+}$, which affects conditions at the higher altitudes, (2) we took assumed NO densities, whereas they calculate the NO densities, and (3) they only considered the low-temperature component of the precipitating flux, whereas we used both the low- and high-temperature components.

\section{Model Results}

The calculations presented here considered three different cases: (1) day-to-night ion flow only ("transport only " case); (2) electron precipitation only ("auroral" case); (3) both sources ("combined" case).

Figure 1 shows our computed ion densities for high solar activity $\left(F_{10.7}=200\right)$ conditions, using as upper boundary conditions at $300 \mathrm{~km}$ the following topside fluxes for the atomic ions: $\mathrm{O}^{+}\left(6.0 \times 10^{7} \mathrm{~cm}^{-2} \mathrm{~s}^{-1}\right), \mathrm{H}^{+}\left(7.0 \times 10^{5} \mathrm{~cm}^{-2} \mathrm{~s}^{-1}\right), \mathrm{C}^{+}\left(3.0 \times 10^{6} \mathrm{~cm}^{-2}\right.$ $\left.\mathrm{s}^{-1}\right), \mathrm{N}^{+}\left(2.4 \times 10^{6} \mathrm{~cm}^{-2} \mathrm{~s}^{-1}\right), \mathrm{He}^{+}\left(9.0 \times 10^{5} \mathrm{~cm}^{-2} \mathrm{~s}^{-1}\right)$. The $\mathrm{O}^{+}$flux was chosen to lead to the electron density values provided by the empirical model of Theis et al. [1984]. This $\mathrm{O}^{+}$flux is about a factor of 4 smaller than the estimated average solar cycle maximum value across the terminator [Knudsen et al., 1980, 1981]; this chosen value of the flux is not inconsistent with the terminator observations, because the flux is expected to decrease

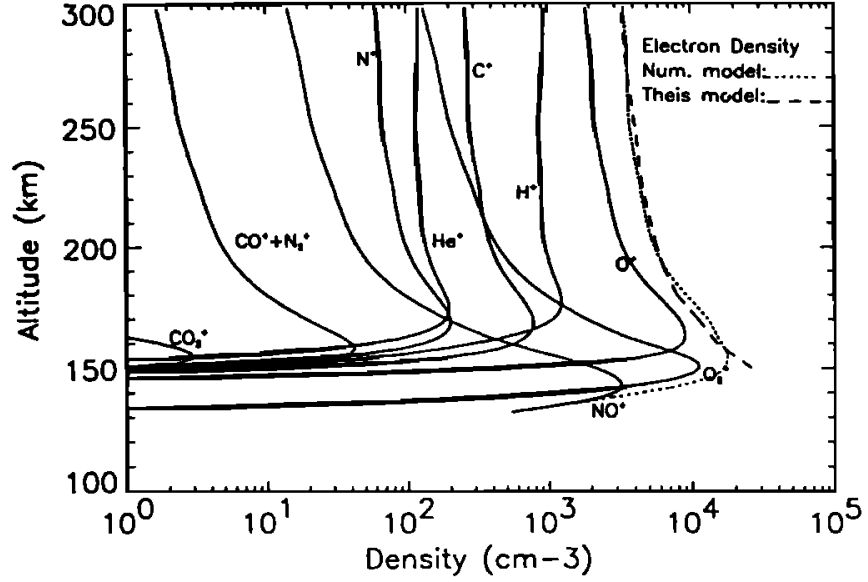

Figure 1. Calculated ion densities for the "transport only," solar maximum condition case. The electron density values from the Theis et al. [1984] model are shown for comparison.

with increasing solar zenith angle. The ratios between the flux values were chosen to be the same as the ion density ratios at the top of the dayside ionosphere for orbit 185 , considered as a typical example of dayside conditions by Taylor et al. [1980]. All the calculations presented here had their lower boundary at $130 \mathrm{~km}$, where chemical equilibrium conditions were assumed to prevail. The calculated electron densities agree well with the observed ones as shown in Figure 1. The peak plasma density is approximately $3 \times 10^{4} \mathrm{~cm}^{-3}$, at an altitude of $153 \mathrm{~km}$. The dominant ion up to this altitude is $\mathrm{O}_{2}^{+}$, even though no $\mathrm{O}_{2}^{+}$is transported from dayside to nightside; above about $152 \mathrm{~km} \mathrm{O}^{+}$becomes dominant. A discussion concerning the comparison of calculated and measured ion composition values is given later, in connection with Figure 4.

Figure 2 shows the computed ion density profiles for the solar maximum auroral case. As we can see, impact ionization alone cannot reproduce the measured electron densities; the calculated electron densities are about an order of magnitude less than the observed values at the top of the ionosphere and a factor of 2-3 less at the ionization peak. It has to be noted that the molecular ions are very sensitive to the presence of precipitating electrons [Fox and Taylor, 1990]. For example we find that the peak density of $\mathrm{CO}_{2}^{+}$increased by more than an order of magnitude compared to the "transport only" case. It should also be noted that the high $(200 \mathrm{eV})$ energy tail in the electron flux accounts for about $50 \%$ of this increase.

A very good agreement between the measured and calculated electron densities can also be obtained if the precipitation source used for the "auroral" case is combined with slightly reduced (16\%) topside flux values from the "transport" case. The results of the calculations for this "combined" case are shown in Figures 3 and 4. The "shoulder" in the $\mathrm{O}_{2}^{+}$profile is due to the superposition of the impact ionization peak and the transport peak.

In Figure 4 we show a comparison between the calculated, "combined" case and observed ion composition values; the observed ion composition values shown correspond to the mean values for the first three Venus years of the PVO mission, as given by Grebowsky et al. [1993]. The calculated atomic ion densities are determined mostly by the topside ion flux values and it should be remembered that the topside $\mathrm{O}^{+}$flux, and thus the other atomic ion fluxes, for this model calculations were set so as to lead to a match between the calculated and observed electron densities. It has been well established, over the life of the PVO mission, that 


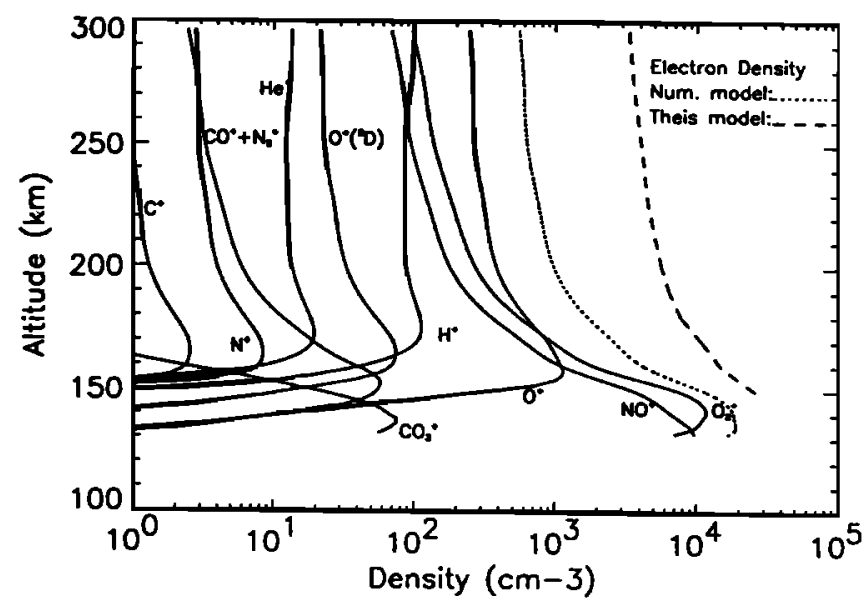

Figure 2. Calculated ion densities for the "auroral only," solar maximum condition case. The electron density values from the Theis et al. [1984] model are shown for comparison.

the absolute ion density values are, on the average, about a factor of 2-3 lower than what is implied from the Langmuir probe based electron density values [cf. Grebowsky et al., 1993]. Therefore in comparing the calculated and measured density values these differences, which are species and flow velocity dependent have to be considered. The observed atomic ion and $\mathrm{O}_{2}^{+}$densities are about a factor of 2 to 3 lower than the calculated values, consistent with the considerations outlined above. The observed $\mathrm{CO}_{2}^{+}$ densities $\left(2-4 \times 10^{1} \mathrm{~cm}^{-3}\right)$ in the 150 to $160 \mathrm{~km}$ region are about a factor of 2 larger than the calculated values. The possible reasons for these high observed values are as follows: 1) these densities are close to the sensitivity threshold of the instrument and 2) given their low thermal velocity they are believed to be most likely to give the right absolute value. The inclusion of metastable oxygen ions, especially $\mathrm{O}^{+}(2 D)$, into the model, resulted in increased mass $28\left(\mathrm{CO}^{2}\right.$ and $\left.\mathrm{NO}_{2}^{+}\right)$ion densities; however it should be noted that our computed mass 28 values are still lower by about an order of magnitude than the measured ones. However, there have been indications that the mass 28 results from the ion mass spectrometer are "suspect," thus any quantitative comparison is difficult.

Next we examined the situation during moderate solar conditions, when the measured densities are substantially lower.

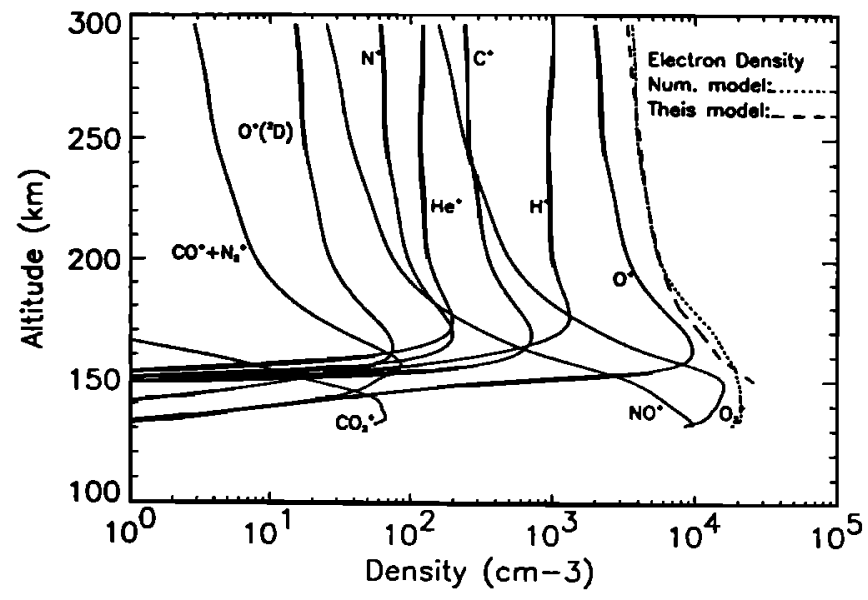

Figure 3. Calculated ion densities for the "combined," solar maximum condition case. The electron density values from the Theis et al. [1984] model are shown for comparison.

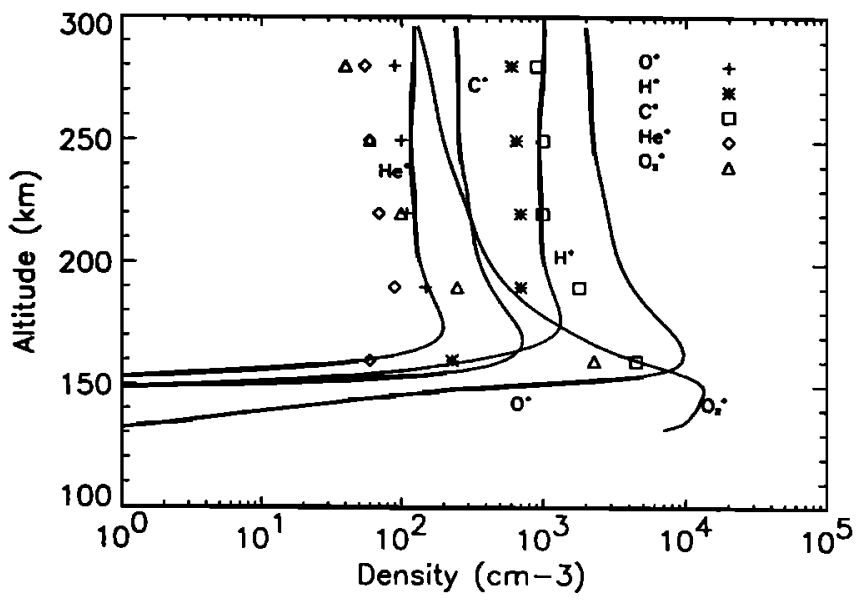

Figure 4. Calculated ion densities for the "combined," solar maximum condition case. The average ion density values measured by the OLMS instrument are shown for comparison [Grebowsky et al., 1993].

In Figure 5 we present our results for the case of day-to-night ion transport only. In order to obtain electron density values close to the measured ones [Theis and Brace, 1993] we needed a topside $\mathrm{O}^{+}$flux value of approximately $2.4 \times 10^{7} \mathrm{~cm}^{-2} \mathrm{~s}^{-1}$. There are no data on the relative dayside ion density values to guide us in the selection of topside flux ratios, thus we selected the following values for the monatomic minor ion flux values, which lead to the observed ion density ratios: $\mathrm{H}^{+}: 2.0 \times 10^{5} \mathrm{~cm}^{-2} \mathrm{~s}^{-1}, \mathrm{C}^{+}: 1.0 \times 10^{6} \mathrm{~cm}^{-2}$ $\mathrm{s}^{-1}, \mathrm{~N}^{+}: 1.3 \times 10^{6} \mathrm{~cm}^{-2} \mathrm{~s}^{-1}$, and $\mathrm{He}^{+}: 2.0 \times 10^{6} \mathrm{~cm}^{-2} \mathrm{~s}^{-1}$. The use of such a lelatively large $\mathrm{O}^{+}$flux does lead to reasonable electron density values, but it does result in $\mathrm{O}^{+}$being the major ion in the $150-200$ $\mathrm{km}$ altitude range, which is contrary to observations, as shown in Figure 8. The model values of the $\mathrm{CO}_{2}^{+}$and mass 28 ion densities are about two orders of magnitude less than the observed ones [Grebowsky et al., 1993] (see Figure 8), possibly providing evidence for the need of an impact ionization source.

Figure 6 shows the calculated ion densities obtained by using the precipitating electron flux, fitted by the two Maxwellian energy distribution functions (same as the solar maximum case). We find that the calculated electron density values for this "auroral only" case are in fairly good agreement, with the electron densities measured during the 1992 entry period by Theis and Brace [1993].

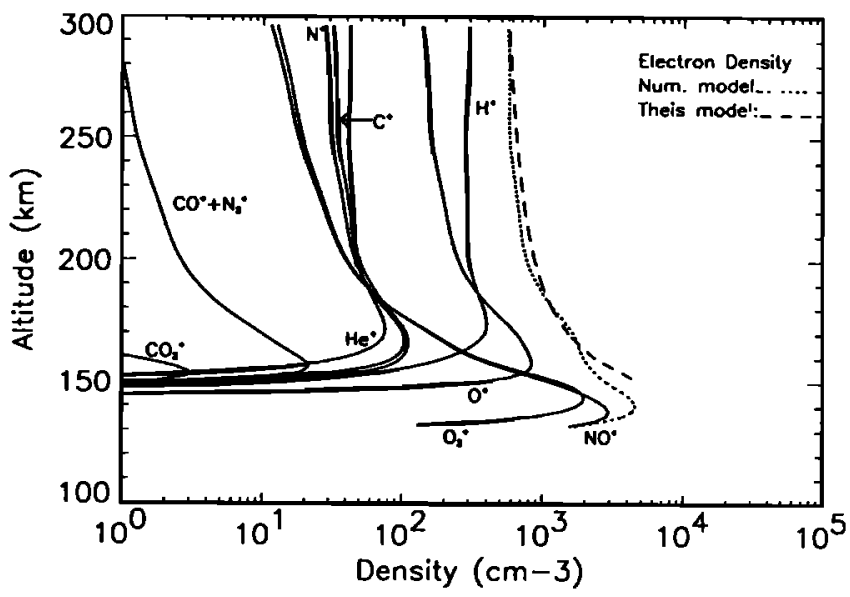

Figure 5. Calculated ion densities for the "transport only," moderate solar condition case. The electron density values from the Theis and Brace [1993] model are shown for comparison. 


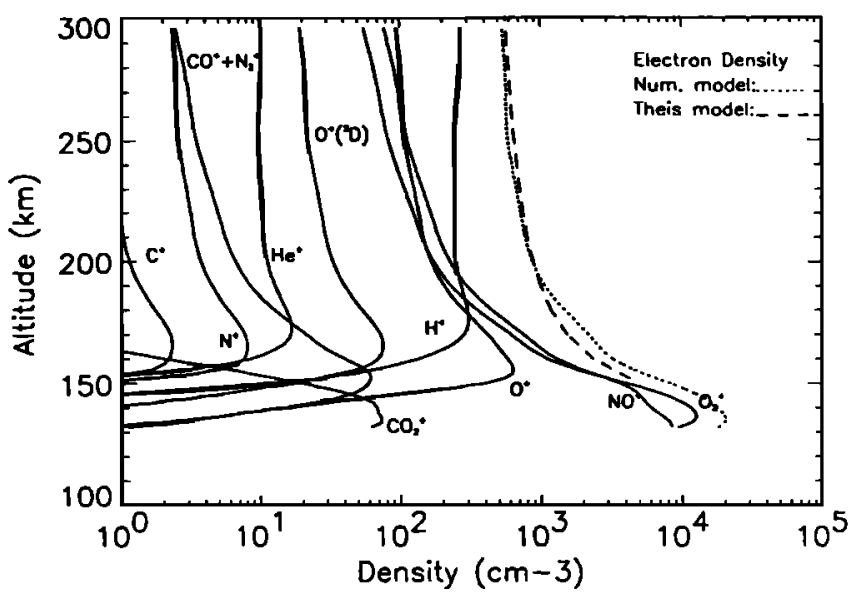

Figure 6. Calculated ion densities for the "auroral only," moderate solar condition case. The electron density values from the Theis and Brace [1993] model are shown for comparison.

In order to achieve better agreement between some of the calculated and measured atomic ion densities the addition of small topside fluxes were helpful $\left(\mathrm{O}^{+}: 1.5 \times 10^{6} \mathrm{~cm}^{-2} \mathrm{~s}^{-1}, \mathrm{H}^{+}: 2.0 \times 10^{4}\right.$ $\mathrm{cm}^{-2} \mathrm{~s}^{-1}, \mathrm{C}^{+}: 6.3 \times 10^{5} \mathrm{~cm}^{-2} \mathrm{~s}^{-1}, \mathrm{~N}^{+}: 7.5 \times 10^{5} \mathrm{~cm}^{-2} \mathrm{~s}^{-1}, \mathrm{He}^{+}: 1.1 \times 10$ $\mathrm{cm}^{-2} \mathrm{~s}^{-1}$ ). We show the results of this "combined case" calculations, together with the mean measured electron density and ion composition values, in Figures 7 and 8, respectively. The ion density results are taken from Grebowsky et al. [1993]. As described earlier, in connection with the solar maximum case, the OIMS derived ion density values have to be used with some caution. Even if only the relative densities are considered, the observations indicate that $\mathrm{O}_{2}^{+}$is the major ion up to about 200 km; this behavior is consistent with the results obtained by both the "auroral only" and the "combined" calculations, but contrary to the "transport only" results. The situation with $\mathrm{CO}_{2}^{+}$and $\mathrm{CO}^{+}, \mathrm{N}_{2}^{+}$is the same as was for the solar maximum case.

\section{Summary and Conclusions}

We modeled the chemical and physical processes taking place in the nightside ionosphere of Venus by solving the one dimensional coupled continuity and momentum equations for 12

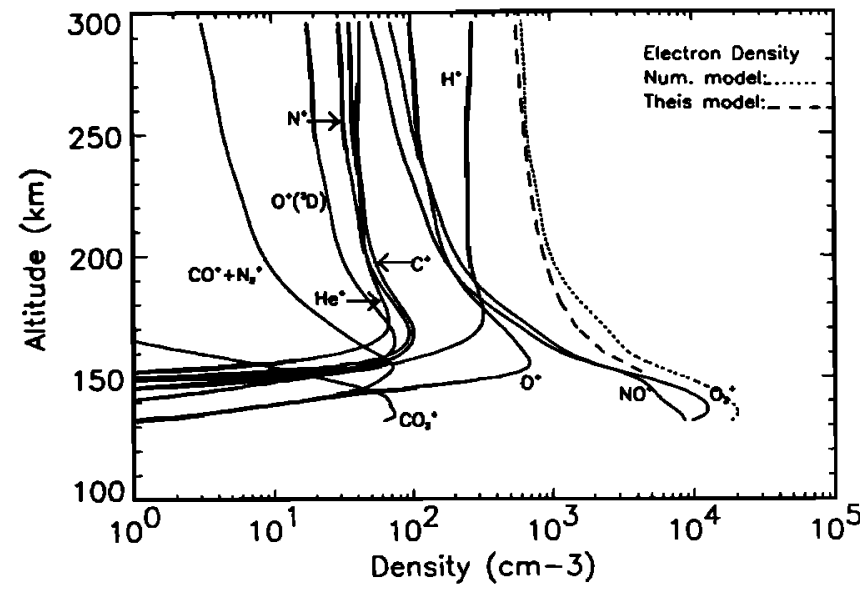

Figure 7. Calculated ion densities for the "combined" moderate solar condition case. The electron density values from the Theis and Brace [1993] model are shown for comparison.

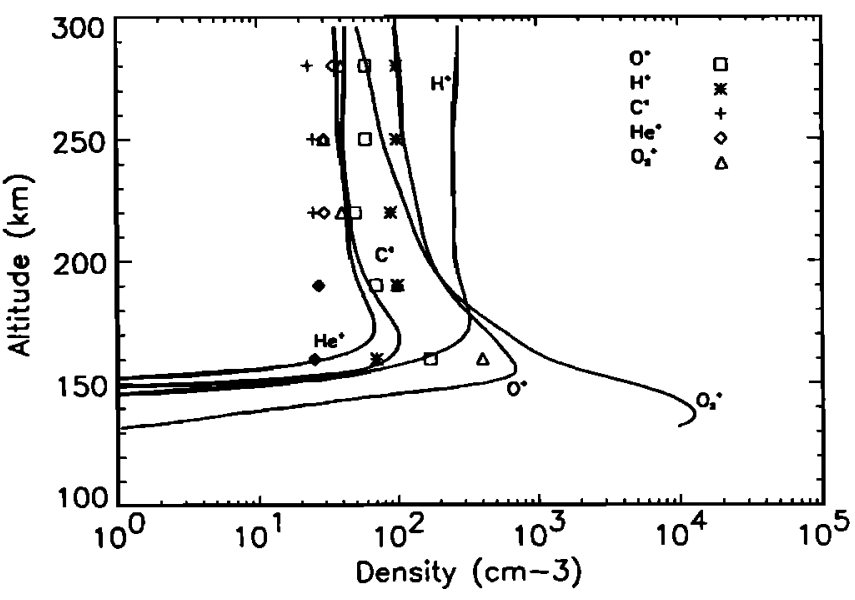

Figure 8. Calculated ion densities for the "combined," moderate solar condition case. The average ion density values measured by the OIMS instrument are shown for comparison [Grebowsky et al., 1993].

ion species $\left[\mathrm{CO}_{2}^{+}, \mathrm{O}_{2}^{+}, \mathrm{O}^{+}, \mathrm{H}^{+}, \mathrm{NO}^{+}, \mathrm{CO}^{+}, \mathrm{N}_{2}^{+}, \mathrm{N}^{+}, \mathrm{He}^{+}, \mathrm{C}^{+}\right.$, $\mathrm{O}^{+}\left({ }^{2} \mathrm{D}\right)$ and $\left.\mathrm{O}^{+}\left({ }^{2} \mathrm{P}\right)\right]$. We investigated the relative importance of the two major processes responsible for maintaining the high nightside plasma densities and relative ion composition: atomic ion transport from the dayside, and impact ionization due to energetic electron precipitation. The impact ionization rates due to the precipitating electrons, measured by the PVO ORPA, were calculated for $\mathrm{CO}_{2}^{+}, \mathrm{O}^{+}, \mathrm{CO}^{+}, \mathrm{N}_{2}^{+}$, and $\mathrm{He}^{+}$using the two stream technique described by Nagy and Banks [1970]. We calculated ion densities corresponding to high $\left(F_{10.7}=200\right.$.) and moderate $\left(F_{10.7}=120\right.$.) solar activity conditions assuming the presence of (1) day-to-night transport only, (2) electron precipitation only, and (3) both sources of nightside ionization. We compared our results with the measured electron and ion density values, provided by PVO OETP and OIMS instruments, for the first 3 years of the mission and the 1992 entry period.

As a result of this comparison, we can conclude that during high solar activity the main plasma source is atomic ion transport from the dayside. We were able to obtain the measured electron density profile by imposing an $\mathrm{O}^{+}$topside flux of $7 \times 10^{7} \mathrm{~cm}^{-2} \mathrm{~s}^{-1}$ to our one dimensional model at $300 \mathrm{~km}$ altitude. We also introduced $\mathrm{H}^{+}, \mathrm{N}^{+}, \mathrm{C}^{+}$, and $\mathrm{He}^{+}$fluxes in the ratio measured by the OnMS on the dayside during high solar activity. The magnitude (about $2 \times 10^{4} \mathrm{~cm}^{-3}$ ) and the height (about $153 \mathrm{~km}$ ) of the electron density peak is determined mainly by the $\mathrm{O}^{+}$inflow. However, it has to be noted that our calculated electron density peak is about 8 $\mathrm{km}$ higher than indicated by the radio occultation measurements. The calculated $\mathrm{O}_{2}^{+}$is dominant between about 145 and $155 \mathrm{~km}$ altitude, and its density peaks at about $150 \mathrm{~km}$. Above about 152 $\mathrm{km} \mathrm{O}^{+}$becomes dominant and has a density peak at about $155 \mathrm{~km}$ altitude. Below an altitude of approximately $145 \mathrm{~km} \mathrm{NO}$ becomes the dominant ion. The presence of the electron precipitation does not affect the major ion densities to any significant degree. The ratios of calculated atomic minor ion densities $\left(\mathrm{H}^{+}, \mathrm{N}^{+}, \mathrm{C}^{+}\right.$, and $\left.\mathrm{He}^{+}\right)$to the $\mathrm{O}^{+}$density are in good agreement with the measured values. These minor atomic ion densities, just like the $\mathrm{O}^{+}$densities, are determined mainly by the imposed topside flux values. The calculated $\mathrm{CO}_{2}^{+}, \mathrm{NO}^{+}$and $\mathrm{N}_{2}^{+} / \mathrm{CO}^{+}$densities depend sensitively on the presence of the impact ionization sources, and electron precipitation has to be included in order to obtain the higher densities, which may be indicated by the observations. Metastable ion species (especially 
of $\mathrm{O}^{+}\left({ }^{2} \mathrm{D}\right)$ ) also increase the calculated $\mathrm{CO}^{2}$ and $\mathrm{N}_{2}^{+}$(mass-28 ion) densities; this conclusion is in agreement with the work of Fox [1982].

Comparing our moderate solar activity model results with the 1992 entry OIMS and OETP data, we can conclude that electron precipitation itself is able to provide the necessary ionization source to maintain the measured nightside peak plasma densities. However, additional day-to-night atomic ion fluxes, one to two orders of magnitude lower than the ones used in the solar maximum case, help to obtain better minor atomic ion $\left(\mathrm{N}^{+}, \mathrm{C}^{+}\right.$and $\mathrm{He}^{+}$) density fits. This suggests that although electron precipitation is able to account for the measured electron and major ion density values, a small day-to-night transport component is likely to be present. This conclusion is based on the assumption that the flux of precipitating electrons does not change with solar cycle; if this assumption is shown to be incorrect by new observations it will clearly have some impact on our results. However, one needs to remember that a solar cycle decrease of a factor of two in the electron flux will cause only an approximately $40 \%$ decrease in the resulting densities and thus would not significantly change our conclusions. Our general conclusions are consistent with the earlier work of Brannon et al. [1993].

The electron densities at the peak are about a factor of 3 , while at higher altitudes about a factor of 10 smaller in the moderate solar cycle auroral model than in the solar maximum transport model. The most prominent solar cycle change, indicated both by the observations and calculations, is the decrease of the $\mathrm{O}^{+}$density by more than an order of magnitude. This change, we believe, is the result of a significant decrease in the day-to-night plasma transport. There is also a significant (about a factor of 4) drop in the $\mathrm{H}^{+}$densities, making the $\mathrm{O}^{+}$and $\mathrm{H}^{+}$densities comparable at moderate solar conditions. The calculated $\mathrm{O}_{2}^{+}$densities, in agreement with the measurements, are about a factor of 3 lower during moderate solar cycle conditions; the peak electron density is still dominated by $\mathrm{O}_{2}^{+}$but $\mathrm{NO}^{+}$is now an important contributor in this region.

There are clearly large day-to-day variations in the height of the ionopause, which controls the effectiveness of the day-to-night transport; as indicated earlier there also appear to be very large changes in the observed electron fluxes. These large variations translate to large variations in the nightside electron densities and ion compositions, which are seen very clearly in the PVO database. Our calculations addressed only the mean nightside conditions. We can conclude that, on the average, the day-tonight atomic ion transport is the most important ionization process during high solar activity, while during moderate solar activity conditions electron precipitation combined with significantly reduced day-to-night ion transport are responsible for maintaining the nightside ionosphere of Venus.

Acknowledgments. The work described in this paper was supported by NASA grants NAG2-491, NAGW-3579 and NAGW-3962 at the University of Michigan and NASA grant NAGW-3731 at SUNY Stony Brook. Support was also received through OTKA grant 18-13 and the USHungarian Joint Fund grant 035/90.

The Editor thanks J.G. Luhmann and another referee for their assistance in evaluating this paper.

\section{References}

Bauer, S.J., L.H. Brace, T.K. Breus, A.J. Kliore, W.C. Knudsen, A.F. Nagy, C.T. Russell, and N.A. Savich, The Venus ionosphere, Adv. Space Res., 5, 233, 1985.
Bougher, S.W., R.E. Dickinson, E.C. Ridley, and R.G. Roble, Venus mesosphere and thermosphere, III. Three dimensional general circulation with coupled dynamics and composition, Icarus, 73, 545. 1988.

Brace, L.H., and A.J. Kliore, The structure of the Venus ionosphere, Space Sci. Rev., S5, 81, 1991.

Brace, L.H., H.A. Taylor, Jr., T.I. Gombosi, A.J. Kliore, W.C. Knudsen, and A.F. Nagy, The ionosphere of Venus: Observations and their interpretation, Venus, edited by D. M. Hunten, L. Colin, T. M. Donahue and V. I. Moroz, p. 779, University of Arizona Press, Tucson, 1983.

Brace, L.H., R.F. Theis, H.B. Niemann, H.G. Mayr, W.R. Hoegy, and A.F. Nagy, Empirical model of the electron temperature and density in the nightside Venus ionosphere., Science, 205, 102, 1979.

Brannon, J.F., J.L. Fox, and H.S. Porter, Evidence for day-to-night transport at low solar activity in the Venus pre-dawn ionosphere, Geophys. Res. Lett., 20, 2739. 1993.

Brinton, H.C., H.A. Taylor, H.B. Niemann, H.G. Mayr, A.F. Nagy, T.E. Cravens, and D.F. Strobel, Venus nighttime hydrogen bulge, Geophys. Res. Lett., 7, 865, 1980.

Butler, D.M., and J.W. Chamberlain, Venus' nightside ionosphere: Its origin and maintenance., J. Geophys. Res., 81, 4757, 1976.

Chen, R.H., and A.F. Nagy, A comprehensive model of the Venus ionosphere, J. Geophys. Res., 83, 1133, 1978.

Cravens, T.E., H.A. Taylor, C.T. Russell, W.C. Knudsen, K.L. Miller, A. Bames, J.D. Mihalov, F. L. Scarf, S.J. Quenon, and A.F. Nagy, Disappearing ionospheres on the nightside of Venus., Icarus, 51, 271, 1982.

Cravens, T.E., S.L. Crawford, A.F. Nagy, and T.I. Gombosi, A twodimensional model of the ionosphere of Venus, J. Geophys. Res., 88, 5595, 1983.

Elphic, R.C., H.G. Mayr, R.F. Theis, L.H. Brace, K.L. Miller, and W.C. Knudsen, Nightward ion flow in the Venus ionosphere: Implications of momentum balance, Geophys. Res. Lett., 11, 1007, 1984.

Fox, J. L., The chemistry of metastable species in the Venusian ionosphere, Icarus, 51, 248, 1982.

Fox, J. L., The chemistry of the nightside ionosphere of Venus, Planet. Space Sci., 14, 1663, 1992.

Fox, J.L., and H.A. Taylor, A signature of electron precipitation in the nightside ionosphere of Venus., Geophys. Res. Lett., 17, 1625, 1990.

Gan, L., Electron distributions and solar wind interaction with nonmagnetic planets, Ph.D. thesis, Univ. of Mich., Ann Arbor, 1991.

Grebowsky, J. M., R. E. Hartle, J. Kar, P. A. Cloutier, H. A. Taylor and L. H. Brace, Ion measurements during Pioneer Venus rentry: Implications for solar cycle variation of ion composition and dynamics., Geophys. Res. Lett., 20, 2735, 1993.

Gringauz, K.I., V.V. Bezrukikh, T.K. Breus, T.I. Gombosi, A.P. Remizov, M.I. Verigin, and G.I. Volkov, Plasma observations near Venus onboard the Venera 9 and 10 satellites by means of wide angle plasma detectors, in Proc.eedings of Physics of Solar Planetary Environments, vol. II, edited by D. J. Williams, p. 918, AGU, Washington, D. C., 1976.

Gringauz, K.I., M.I. Verigin, T.K. Breus, and T.I. Gombosi, The interaction of electrons in the optical umbra of Venus with the planetary atmosphere-The origin of the nightside ionosphere, $J$. Geophys. Res., 84, 2123, 1979.

Hedin, A.E., H.B. Niemann, W.T. Kasprzak, and A. Seiff, Global empirical model of the Venus themosphere, J. Geophys. Res., 88, 73, 1983.

Kasprzak, W.T., H.B. Niemann, A.E. Hedin, S.W. Bougher, and D.M. Hunten, Neutral composition measurements by the Pioneer Venus neutral mass spectrometer during orbiter re-entry, Geophys. Res. Lett., 20, $2747,1993$.

Keating, G.M., J.L. Bertaux, S.W. Bougher, T.E. Cravens, R.E. Dickinson, A.E. Hedin, V.A. Krasnapolsky, A.F. Nagy, J.Y. Nicholson, L.J. Paxton, and U.V. Zahn, Models of Venus neutral upper atmosphere: Structure and composition, Adv. Space Res., S, 117, 1985.

Kim, J., A.F. Nagy, T.E. Cravens, and A.J. Kliore, Solar cycle variations of the electron densities near the ionospheric peak of Venus, $J$. Geophys. Res., 94, 11, 1989. 
Kliore, A.J., G.S. Levy, D.L. Cain, G. Fjeldbo, and S.I. Rasool, Atmosphere and ionosphere of Venus from the Mariner 5 S-band occultation measurement, Science, 158, 1683, 1967.

Knudsen, W. C., and K. L. Miller, Pioneer Venus superthermal eleciron flux measurements in the Venus umbra, J. Geophys. Res., 90, 2695, 1985.

Knudsen, W.C., K. Spenner, K.L. Miller, and V. Novak, Transport of ionospheric $\mathrm{O}+$ ions across the Venus teminator and implications., $J$. Geophys. Res., 85, 7803, 1980.

Knudsen, W.C., K. Spenner, and K.L. Miller, Anti-solar acceleration of ionospheric plasma across the Venus terminator, Geophys. Res. Lett., 8, $241,1981$.

Krasnapolsky, V.A., Nightside ionosphere of Venus., Planet. Space Sci., 27, 1403, 1979.

McElroy, M.B., The upper atmosphere of Venus, J. Geophys. Res., 73, 1513, 1968.

McElroy, M.B., and D.F. Strobel, Models for the nighttime Venus ionosphere, J. Geophys. Res., 74, 1118, 1969.

Nagy, A.F., T.E. Cravens, and T.I. Gombosi, Basic theory and model calculations of the Venus ionosphere, in Venus, edited by D. M. Hunten, L. Colin, T. M. Donahue and V. I. Moroz, p. 841, University of Arizons Press, Tucson, 1983.

Nagy, A.F., A. Korosmezey, J. Kim, and T.I. Gombosi, A two dimensional shock capturing hydrodynamic model of the Venus ionosphere, Geophys. Res. Lett., 18, 801, 1991.

Schunk, R.W., and A.F. Nagy, Ionospheres of the terrestrial planets, Rev. Geophys., 18, 813, 1980.

Spenner, K., W.C. Knudsen, R.C. Whitten, P.F. Michalson, K.L. Miller, and $V$. Novak, On the maintenance of the Venus nightside ionosphere:
Electron precipitation and plasma transport, J. Geophys. Res., 86, 9170, 1981.

Taylor, Jr., H.A., H.C. Brinton, S.J. Baver, R.E. Hartle, P.A. Cloutier, and R.E. Daniell, Jr. Global observation of the composition and dynamics of the Ionosphere of Venus: Implications for the solar wind interaction. J. Geophys. Res., 85, 7765, 1980.

Theis, R.F., and L.H. Brace, Solar cycle variations of electron density and temperature in the Venusian nightside ionosphere, Geophys. Res. Lett. $20,2719,1993$.

Theis, R.F., L.H. Brace, R.C. Elphic, and H.G. Mayr, New empirical models of the electron temperature of the Venus ionosphere with application to transterminator flow, J. Geophys. Res., 89, 1477, 1984.

Whitten, R.C., P.T. McCormick, D. Merritt, K.W. Thompson, R.R. Brynsvold, C.J. Eich, W.C. Knudsen, and K.L. Miller, Dynamics of the Venus ionosphere: A two-dimensional model study, Icarus, 60 , $317,1984$.

Z. Dobe and A. F. Nagy, Space Physics Research Laboratory, Department of Atmospheric, Oceanic and Space Sciences, University of Michigan, Ann Arbor, MI 48109.

J. L. Fox, Institute for Terrestrial and Planetary Atmospheres, State University of New York at Stony Brook, Stony Brook, NY 11794.

(Received June 24, 1994; revised January 23, 1995; accepted January 26, 1995.) 